\title{
Augmentation of Heroin Seeking Following Chronic Food Restriction in the Rat: Differential Role for Dopamine Transmission in the Nucleus Accumbens Shell and Core
}

\author{
Tracey M D’Cunha', Emilie Daoud', Damaris Rizzo', Audrey B Bishop', Melissa Russo', Gabrielle Mourra', \\ Laurie Hamel', Firas Sedki' and Uri Shalev*,I \\ 'Department of Psychology, Center for Studies in Behavioral Neurobiology/Groupe de Recherche en Neurobiologie Comportementale, Concordia \\ University, Montreal, QC, Canada
}

\begin{abstract}
Caloric restriction during drug abstinence increases the risk for relapse in addicts. In rats, chronic food restriction during a period of withdrawal following heroin self-administration augments heroin seeking. The mechanisms underlying this effect are largely unknown. Here, we investigated the role of nucleus accumbens (NAc) shell and core dopamine (DA) in food restriction-induced augmentation of heroin seeking. Rats were trained to self-administer heroin $(0.1 \mathrm{mg} / \mathrm{kg} /$ infusion) for 10 days. Next, rats were moved to the animal colony for a withdrawal period, during which rats were food restricted to $90 \%$ of their original body weight (FDR group) or given unrestricted access to food (sated group). On day 14 of food restriction, rats were returned to the operant conditioning chambers for a heroin-seeking test under extinction conditions. Extracellular DA levels were assessed using in vivo microdialysis. In separate experiments, the DA DI-like receptor antagonist SCH39|66 (I2.5, 25.0, or $50.0 \mathrm{ng} /$ side) was administered into the NAc before the heroin-seeking test. In the NAc shell, pre-test exposure to the heroin-associated context increased DA only in FDR rats; but in the NAc core, DA increased regardless of feeding condition. Food restriction significantly augmented heroin seeking and increased DA in the NAc shell and core during the test. Intra-NAc shell administration of SCH39166 decreased heroin seeking in all rats. In contrast, in the NAc core, SCH39I66 selectively decreased the augmentation of heroin-seeking induced by chronic food restriction. Taken together, these results suggest that activation of the DA DI-like receptor in the NAc core is important for food restriction-induced augmentation of heroin seeking.

Neuropsychopharmacology (20 I7) 42, I I36-I |45; doi: I 0.1038/npp.20 16.250; published online 7 December 2016
\end{abstract}

\section{INTRODUCTION}

In humans, a reciprocal association exists between the abuse of drugs like tobacco, cocaine and heroin, and food intake. Drug use decreases food intake, and caloric restriction can increase drug consumption, craving, and relapse. For example, the level of dietary restriction has been positively correlated with the use of alcohol, cigarettes, and marijuana in young women (Krahn et al, 1992). Furthermore, the risk for relapse in abstinent smokers is higher in subjects that are concurrently calorie restricted (Hall et al, 1992). Prolonged food restriction seems to be a critical factor, since shorter food restriction period (24-72 h) did not change cigarette smoking (Cheskin et al, 2005) or responses to intravenous fentanyl administration (Zacny et al, 1992). In animal models of addiction and relapse, caloric restriction reliably augments

* Correspondence: Dr U Shalev, Department of Psychology, Center for Studies in Behavioral Neurobiology/Groupe de Recherche en Neurobiologie Comportementale, Concordia University, 7I4I Sherbrooke Street West, Montreal, QC, H4B IR6, Canada, Tel: +5|4 8482424 , Fax: +514848 2817, E-mail: uri.shalev@concordia.ca

Received 7 July 20 16; revised 16 October 2016; accepted 2 November 2016; accepted article preview online 8 November 2016 drug taking and seeking. Both acute food deprivation (complete removal) and chronic food restriction (prolonged, restricted availability) increase self-administration of a variety of substances, including opiate and psychostimulant drugs (Carroll and Meisch, 1981; Carroll and Meisch, 1984), and the conditioned rewarding properties of morphine in the conditioned place preference paradigm (CPP; Gaiardi et al, 1987; Jung et al, 2016). Recently, we found that chronic (14 days) food restriction augments heroin seeking in rats under prolonged withdrawal (D'Cunha et al, 2013).

The neural mechanisms underlying the augmentation of heroin-seeking induced by chronic food restriction remain unknown. However, drug- and food-associated cues have been found to elicit significant elevations in extracellular dopamine (DA) levels in the nucleus accumbens (NAc) shell and core (Bassareo et al, 2011). In addition, chronic food restriction increases DA receptor signaling in the NAc (Carr et al, 2003).

Here, we investigated the role of DA transmission in the NAc in food restriction-induced augmentation of heroin seeking. We used in vivo microdialysis to determine changes in extracellular DA in the NAc shell and core. Previous studies suggest that DA D1-like receptors are important for 
context- and discriminative cue-induced reinstatement of heroin, cocaine, and natural rewards seeking (Marchant et al, 2015). Moreover, we have recently reported that blockade of DA D1-, but not D2-like receptors, attenuated acute food deprivation-induced reinstatement of heroin seeking (Tobin et al, 2013). In addition, chronic food restriction increases synaptic plasticity in NAc cells expressing DA D1-like, but not D2-like, receptors (Carr et al, 2003, 2010). Consequently, here we administered a DA D1-like receptor antagonist into the NAc shell and core to determine if DA transmission via the D1-like receptors is causally related to the augmentation of heroin-seeking induced by chronic food restriction.

\section{MATERIALS AND METHODS}

\section{Subjects}

Male Long Evans rats (Charles River, St. Constant, Quebec, Canada; $n=196$ ) were used in six different experiments. Rats were pair-housed until surgery, and then individually housed after surgery (see Supplementary Material for further details on housing).

All rats were treated in accordance with the guidelines of the Canadian Council on Animal Care and approval for all procedures was granted by the Concordia University Animal Research Ethics Committee.

\section{Surgical Procedures}

Intravenous catheterization was completed under ketamine and xylazine (90.0 and $13.0 \mathrm{mg} / \mathrm{kg}$, i.p.) as previously described (Sedki et al, 2013). Following surgery rats were given penicillin (450 $000 \mathrm{IU} / \mathrm{rat}$, s.c.) and the analgesic ketoprofen $(5 \mathrm{mg} / \mathrm{kg}$, s.c., CDMV, Quebec, Canada). For rats in the microdialysis experiments, unilateral guide cannulae, counterbalanced between the right and left hemispheres, were implanted targeting the NAc shell (Experiment 1) or NAc core (Experiment 2) during the intravenous surgical procedure (Ito et al, 2000). For DA receptor antagonist administration, bilateral guide cannulae targeting the NAc shell (Experiment 3) or NAc core (Experiment 4) were implanted during the intravenous surgical procedure (Tobin et al, 2013). See also Supplementary Material.

\section{Apparatus}

Operant conditioning chambers (Med Associates Inc., St Albans, VT; or Coulbourn Instruments, Holliston, MA) equipped with two levers were used. See also Supplementary Material.

\section{Drugs}

Heroin (diacetylmorphine $\mathrm{HCl}$; National Institute for Drug Abuse, Research Triangle Park, NC, USA) was dissolved in physiological saline and delivered at a dose of $0.1 \mathrm{mg} / \mathrm{kg} /$ infusion. The DA D1-like receptor antagonist SCH39166 (Tocris Bioscience, Minneapolis, MN, USA) was diluted in sterile saline to produce the following doses: 0.0, 12.5, 25.0, $50.0 \mathrm{ng} / \mathrm{side}$. These doses were previously shown to impair the acquisition of morphine conditioned place preference with minimal motor side-effects (Fenu et al, 2006).

\section{Procedure}

Different rats were used for each of the experiments, which followed a similar procedure. There were three phases: heroin self-administration training in the operant conditioning chambers, a withdrawal phase in the animal care facility (ACF), and a testing phase in the operant conditioning chambers, or in clear Plexiglas chambers (context control experiments).

Training. Following two post-surgery recovery days, rats underwent daily three 3 -h sessions separated by a $3 \mathrm{~h}$ period, under a fixed-interval-20 (FI-20) schedule of heroin reinforcement $(0.1 \mathrm{mg} / \mathrm{kg} /$ infusion $)$, as previously described (D'Cunha et al, 2013), over 10 days. Active lever responses resulted in a heroin infusion and initiation of a $20 \mathrm{~s}$ timeout period during which a tone-light compound cue was activated. Active lever responses made during the timeout were recorded but not reinforced. Inactive lever responses were recorded but had no programmed consequences. See also Supplementary Material.

Withdrawal and food restriction. Following the heroin self-administration phase, rats were transferred back to the ACF and housed in individual cages. After a $24 \mathrm{~h}$ drug washout period, rats were matched for number of infusions, active lever responses, and body weight during the last 5 days of training and assigned to a food restricted (FDR) or sated group. FDR rats were fed daily at 13:30 hours and the food ration was adjusted daily to bring the body weight of the FDR group to $\sim 90 \%$ of their first withdrawal day body weight.

In vivo microdialysis and heroin-seeking tests. Approximately $14 \mathrm{~h}$ before the heroin-seeking test, microdialysis probes (Bioanalytical Systems Inc., West Lafayette, IN, USA, or made in the laboratory; Sorge et al, 2005) were lowered into the targeted brain region, under light isoflurane anesthesia. Probes targeted at the NAc shell (Experiment 1) had a $2.0 \mathrm{~mm}$ semipermeable active membrane $(280 \mu \mathrm{m}$ OD), whereas probes targeted at the NAc core (Experiment 2) had a $1.5 \mathrm{~mm}$ active membrane. Baseline collection started in the ACF, and dialysate samples were collected every $10 \mathrm{~min}$ over $1 \mathrm{~h}$ at a flow rate of $1.0 \mu \mathrm{l} / \mathrm{min}$. Next, rats were transported from the animal facility to the drug self-administration training room (Experiments $1 \mathrm{~A}$ and $2 \mathrm{~A}$ ) or to an unfamiliar room for the context-change control experiments (1B and $2 \mathrm{~B}$ ). Microdialysis pumps were plugged into a battery pack so that the flow rate and sampling continued during transfer. Rats were then transferred to the operant conditioning chambers for the heroin-seeking test (Experiments 1A, 2A) or to a Plexiglas chamber (Experiments $1 \mathrm{~B}, 2 \mathrm{~B})$. After the move to the testing chamber, but before the initiation of the test, one dialysate sample was collected (corresponding with the context change). Testing took place under extinction conditions over a 3-h session, and dialysate samples were collected every $10 \mathrm{~min}$. Active lever responses resulted in the same consequences as in training except that no heroin infusions occurred. No levers 
or cues were presented in the Plexiglas chambers. See also Supplementary Material.

Intracranial injections and heroin-seeking tests. Rats were administered the D1-like receptor antagonist, SCH39166, $\sim 10 \mathrm{~min}$ before the heroin-seeking test (Experiments 3 and 4). Testing took place under extinction conditions over one 3-h session. See also Supplementary Material.

\section{Analytical Chemistry}

Extracellular DA was isolated in the dialysate samples using high performance liquid chromatography and quantified using electrochemical detection as previously described (Sorge et al, 2005). See also Supplementary Material.

\section{Statistical Analysis}

Statistical analyses were conducted using SPSS (IBM, SPSS Statistics, version 20). Data were analyzed using ANOVA followed by post-hoc tests with Bonferroni correction for multiple comparisons where appropriate. See also Supplementary Material.

\section{RESULTS}

For experiments 1 and 2, 60 rats were trained, but 10 rats were excluded due to technical problems or incorrect probe placement (Figures 1a and b). For experiments 3 and 4, 136 rats were trained, but 24 rats were removed due to incorrect cannulae placements (Figures $1 \mathrm{c}$ and d). All rats acquired reliable heroin self-administration behavior Supplementary Table Sl. In all experiments, at test day the food-restricted rats were at $\sim 90 \%$ of their body weight at the start of the withdrawal phase Supplementary Table Sl. Mean body weights of rats in the sated and FDR groups throughout the experiments are presented in Supplementary Figure S1 A-F.

\section{Experiment 1A: Changes in Extracellular DA in the NAc Shell}

Behavior. Exposure to 14 days of food restriction resulted in a robust overall augmentation of active lever responses made by the FDR $(n=10)$ compared with the sated group $(n=8$; Figure $2 \mathrm{a}$ inset). Active lever responses recorded in 10 min bins (Figure 2a) were higher in the FDR rats (feeding condition: $\left.F_{(1,16)}=7.769, \quad p=0.013, \eta^{2}=0.327\right)$, with a statistically significant decrease over time $\left(F_{(17,272)}=9.131\right.$, $\left.p<0.001, \eta^{2}=0.344\right)$ but no interaction of feeding condition $\times$ time $\left(F_{(17,272)}=1.388, p=0.142, \eta^{2}=0.052\right)$. There were no statistically significant differences between groups in the number of inactive lever responses.

Microdialysis. There were no statistically significant differences in absolute baseline dialysate concentrations of DA (Table 1). Chronic food restriction resulted in increased extracellular DA throughout the sampling period (Figure 2b; feeding condition: $\left.F_{(1,16)}=4.699, p=0.046, \eta^{2}=0.227\right)$, and there were no statistically significant effects for time $\left(F_{(18,288)}=1.202, p=0.258, \eta^{2}=0.065\right)$, or feeding condition $\times$ time $\left(F_{(18,288)}=1.158, p=0.296, \eta^{2}=0.063\right)$. Planned comparisons revealed a statistically significant increase in extracellular DA in FDR rats compared with baseline following exposure to the heroin self-administration context $\left(t_{(9)}=-2.316, p=0.046, d=1.544\right.$; Figure 2b). Extracellular DA at the initiation of the heroin-seeking test was elevated in the FDR rats compared with baseline levels $\left(t_{(9)}=-3.951\right.$, $p=0.003, d=2.634)$ and to sated rats $\left(t_{(16)}=3.080, p=0.007\right.$, $d=1.54$; Figure 2b).

\section{Experiment 1B: Specificity of Changes in Extracellular DA in the NAc Shell to the Drug Context}

In a separate group of rats, following heroin selfadministration training and 14 days of food restriction as in Experiment 1, rats were transferred to an unfamiliar room and into a Plexiglas chamber (novel context). Absolute baseline dialysate concentrations of DA were not statistically significantly different between $\operatorname{FDR}(n=5)$ and sated rats $(n=4$; Table 1$)$. There were no changes in extracellular DA in either the FDR or sated groups as compared with baseline (Figure 2c; feeding condition: $F_{(1,7)}=0.339, p=0.579$, $\eta^{2}=0.046$; time: $F_{(19,133)}=1.399, p=0.138, \eta^{2}=0.144$; feeding condition $\times$ time: $\left.F_{(19,133)}=1.325, p=0.178, \eta^{2}=0.136\right)$.

\section{Experiment 2A: Changes in Extracellular DA in the NAc Core}

Behavior. FDR rats $(n=9)$ displayed a considerable increase in the total number of responses on the active lever compared with sated rats ( $n=5$; Figure $3 \mathrm{a}$ inset). Active lever responses recorded in 10 min bins in FDR rats were substantially higher than in sated rats over the first $20 \mathrm{~min}$ of the test session (Figure 3b; feeding condition: $F_{(1,12)}=5.218, \quad p=0.041$, $\eta^{2}=0.303$; time: $F_{(17,204)}=6.281, P<0.001, \eta^{2}=0.297$; feeding condition $\times$ time: $\left.F_{(17,204)}=2.858, p<0.001, \eta^{2}=0.135\right)$. There were no statistically significant differences in the number of inactive lever responses between groups.

Microdialysis. There were no statistically significant differences in absolute baseline dialysate concentrations of DA (Table 1). Extracellular DA in the NAc core increased following the move to the operant conditioning chamber, but decreased back to baseline during the test session (Figure 3b; time: $\left.F_{(19,228)}=7.630, p=0.007, \eta^{2}=0.075\right)$. There were no statistically significant effects for feeding condition $\left(F_{(1,12)}=0.979, p=0.342, \eta^{2}=0.367\right)$ or feeding condition $\times$ time $\left(F_{(19,228)}=1.174, p=0.282, \eta^{2}=0.056\right)$. Planned comparisons found that both the FDR rats $\left(t_{(8)}=-3.166\right.$, $p=0.01, d=2.239)$, and the sated rats $\left(t_{(4)}=-3.959\right.$, $p=0.017, d=3.959)$ demonstrated a statistically significant increase in extracellular DA following exposure to the operant chamber compared with baseline levels. However, extracellular DA remained elevated compared with baseline following the initiation of the heroin-seeking test in only the FDR rats $\left(t_{(8)}=-3.226, p=0.012, d=2.281\right)$ before returning back to basal levels.

\section{Experiment 2B: Specificity of Changes in Extracellular DA in the NAc Core to the Drug Context}

Absolute baseline dialysate concentrations of DA in the NAc core did not differ between FDR $(n=4)$ and sated $(n=5)$ 



Figure I Cannula placements for all experiments. Approximate locations of active region of microdialysis probe targeting the NAc shell (a) for Experiment IA ( $n=18$; black rectangles) and Experiment IB ( $n=9$; gray rectangles), or the NAc core (b) for Experiment $2 \mathrm{~A}(n=14$; black rectangles) and Experiment $2 \mathrm{~B}$ ( $n=9$; gray rectangles). Approximate anatomical position for microinjector tips targeting the NAc shell (c) for Experiment 3 ( $n=66$; open circles) or NAc core (d) for Experiment 4 ( $n=46$; open triangles). Images modified from the brain atlas of Paxinos and Watson (2005) of Figures I7-20 (+ I.56 to + I.92 mm anterior to Bregma).

groups. FDR rats displayed a short-term increase in NAc core extracellular DA after the move to the novel chamber (Figure 3c; feeding condition: $F_{(1,7)}=1.177, p=0.314$, $\eta^{2}=0.144$; time: $F_{(19,133)}=2.484, p=0.001, \eta^{2}=0.202$; feeding condition $\times$ time: $\left.F_{(19,133)}=2.786, p<0.001, \eta^{2}=0.227\right)$. Planned comparisons revealed that the increase from baseline in extracellular DA in the FDR rats following exposure to the novel context did not reach statistical significance $\left(t_{(3)}=-2.376, p=0.098, d=2.744\right)$, but was statistically significantly higher than the in sated rats $\left(t_{(7)}=2.823\right.$, $p=0.026, d=2.134$ ).

\section{Experiment 3: Administration of the DA D1-like Receptor Antagonist, SCH39166, into the NAc Shell}

The final analysis included the following 8 groups: FDR-0.0 ng $\quad(n=8), \quad$ FDR-12.5 ng $\quad(n=8), \quad$ FDR-25.0 ng $(n=8), \quad$ FDR-50.0 ng $(n=8)$, sated-0.0 ng $(n=9)$, sated$12.5 \mathrm{ng}(n=9)$, sated-25.0 $\mathrm{ng}(n=8)$, and sated-50.0 $\mathrm{ng}$ $(n=8)$. Overall, the FDR groups responded more on the active lever during the 3-h heroin-seeking test compared with the sated groups (Figure 4a; feeding condition: $F_{(1,58)}=20.35$, $\left.p<0.001, \eta^{2}=0.234\right)$. Administration of SCH39166 into the 

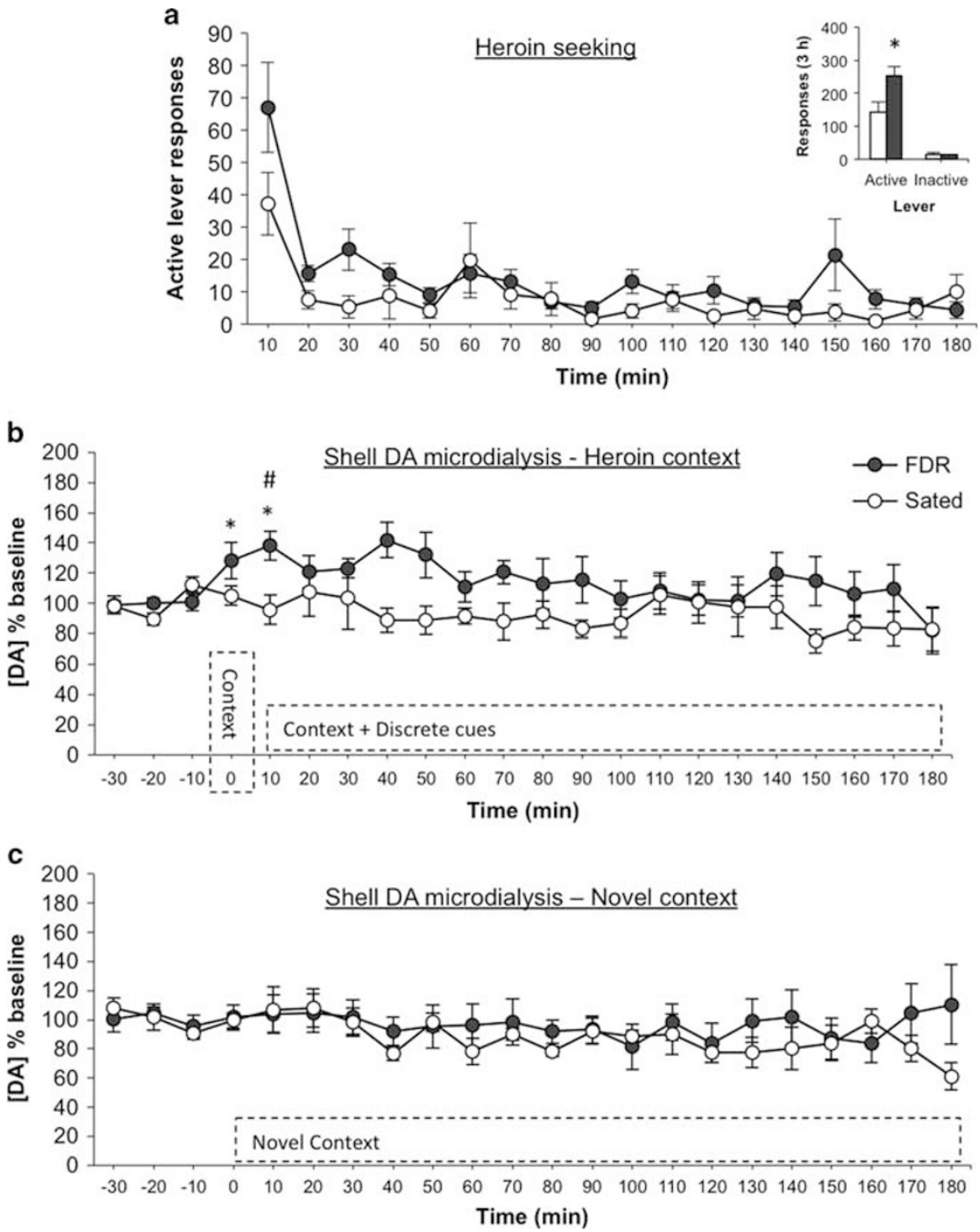

Figure 2 Chronic food restriction-induced augmentation of heroin seeking and extracellular dopamine in the NAc shell. (a) Total number of active and inactive lever responses for FDR $(n=10)$ and sated $(n=8)$ rats (inset), and active lever responses in I0-min time intervals during the $3 \mathrm{~h}$ heroin-seeking test in Experiment I, $* p=0.013$ compared with sated rats. (b) Extracellular dopamine following re-exposure to the drug environment and during the heroin seeking test in the FDR and sated rats, $* 00.05$ compared with baseline levels, $\# p=0.007$ compared to sated rats. (c) Extracellular dopamine following exposure to a novel context in the FDR $(n=5)$ or sated $(n=4)$ rats.

Table I Mean \pm SEM of the Absolute Concentrations of Baseline Dopamine Levels of the FDR and Sated Rats

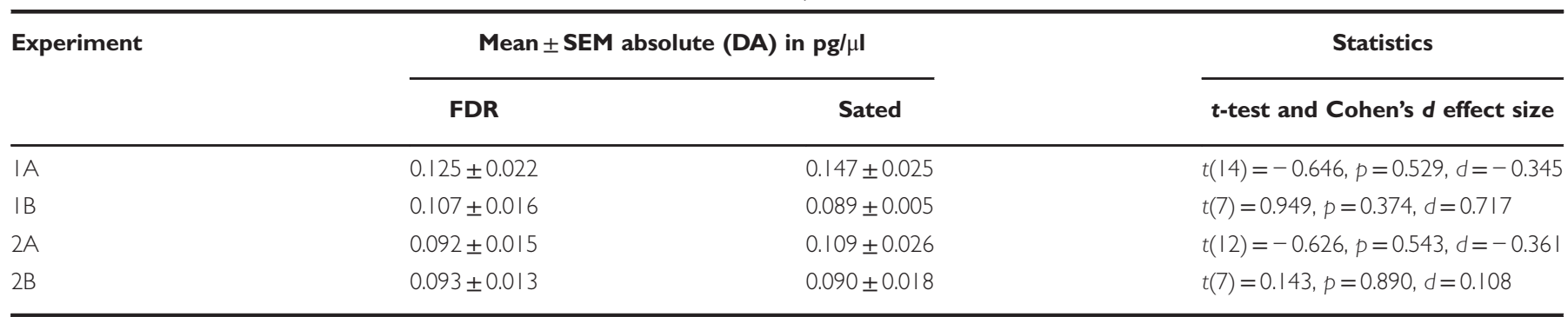

NAc shell statistically significantly decreased active lever responding regardless of food restriction condition $\left(\right.$ SCH39166 dose: $\left.F_{(3,58)}=2.765, p=0.05, \eta^{2}=0.095\right)$. No statistically significant effect for feeding condition $x$
SCH39166 dose interaction was observed $\left(F_{(3,58)}=0.100\right.$, $\left.p=0.959, \quad \eta^{2}=0.003\right)$. Finally, no statistically significant effects were observed for inactive lever responding during the test. 

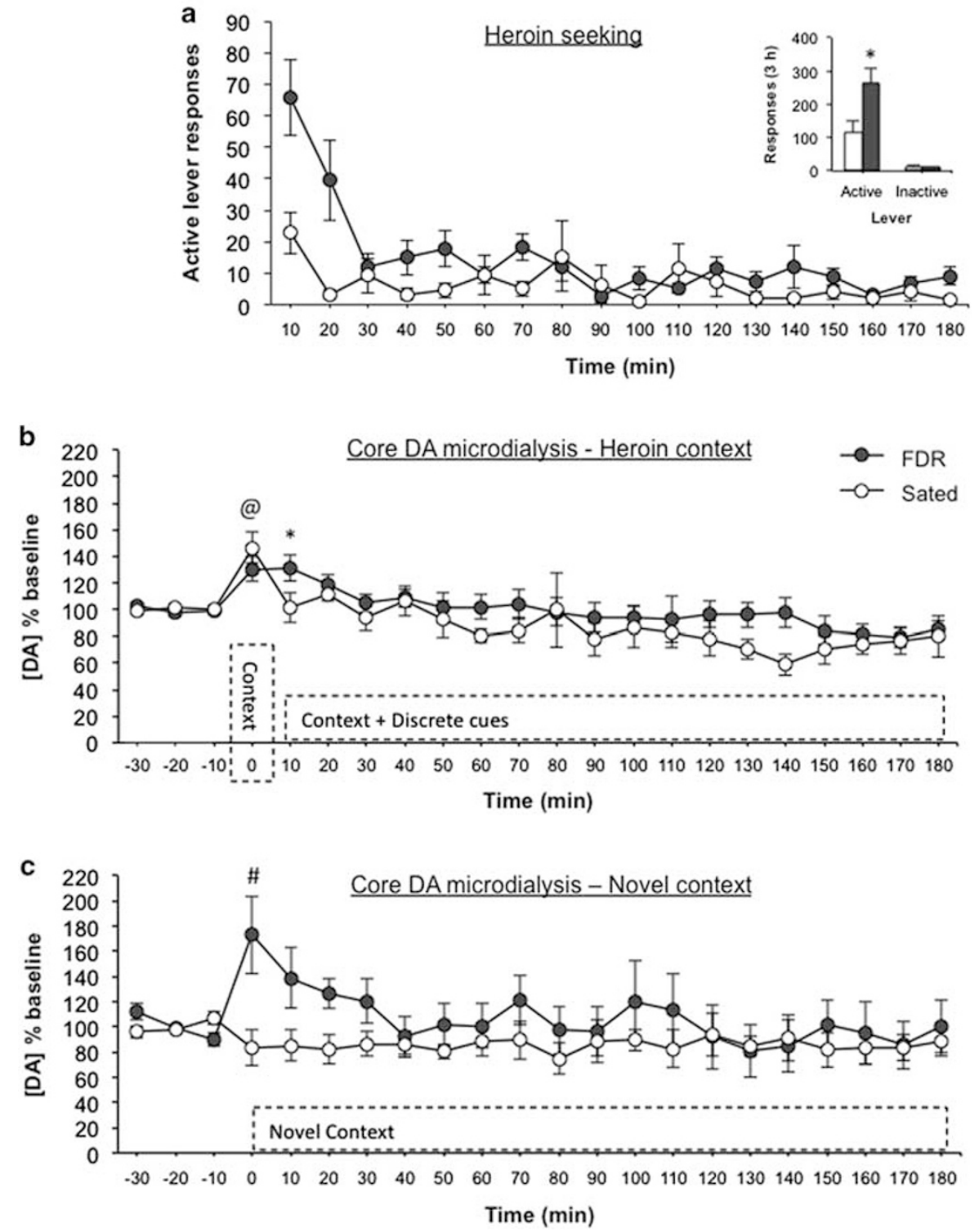

Figure 3 Chronic food restriction-induced augmentation of heroin seeking and extracellular dopamine in the NAc core. (a) Total number of active and inactive lever responses for FDR $(n=9)$ and sated $(n=5)$ rats (inset), and active lever responses in 10-min time intervals during the 3-h heroin-seeking test in Experiment 2. ${ }^{*} p=0.041$ compared to sated rats. (b) Extracellular dopamine following re-exposure to the drug environment and during the heroin-seeking test in the FDR and sated rats, ${ }^{@} p<0.05$ FDR and sated groups compared to baseline, ${ }^{*} p=0.012$ FDR group compared to baseline. (c) Extracellular dopamine following exposure to a novel context in FDR $(n=4)$ and sated $(n=5)$ rats, ${ }^{*} p=0.026$ compared to sated rats.

\section{Experiment 4: Administration of the DA D1-Like Receptor Antagonist, SCH39166, into the NAc Core}

The final analysis included the following 6 groups: FDR-0.0 ng $\quad(n=8), \quad$ FDR-12.5 ng $\quad(n=9), \quad$ FDR-25.0 ng $(n=7)$, sated-0.0 $\mathrm{ng}(n=7)$, sated- $12.5 \mathrm{ng}(n=7)$, and sated$25.0 \mathrm{ng}(n=8)$. Overall, the FDR groups responded more on the active lever during the 3-h heroin-seeking test compared with the sated groups (Figure $4 \mathrm{~b}$; feeding condition: $\left.F_{(1,40)}=22.703, p<0.001, \eta^{2}=0.314\right)$, but there was no main effect for SCH39166 dose: $F_{(2,40)}=0.891, p=0.418$, $\left.\eta^{2}=0.025\right)$. Importantly, there was a statistically significant interaction between feeding condition $\times \mathrm{SCH} 39166$ dose $\left(F_{(2,40)}=3.86, p=0.029, \eta^{2}=0.107\right)$. Bonferroni's post-hoc analyses revealed a statistically significant higher number of responses in the FDR-0.0 ng group compared with the sated-0.0 ng group $\left(t_{(40)}=4.967, p<0.0001\right)$, but no differences between the FDR-12.5 ng and sated-12.5 ng groups, or between the FDR-25.0 ng and sated-25.0 ng groups. In addition, the number of active lever responses made by the FDR-0.0 ng group was statistically significantly higher than the FDR-12.5 ng group $\left(t_{(40)}=2.847, p=0.02\right)$, but not the FDR-25.0 ng $\left(t_{(40)}=2.283, p=0.08\right)$. Finally, no statistically significant effects were observed for inactive lever responding during the test.

\section{DISCUSSION}

Chronic food restriction augmented heroin seeking following two weeks of withdrawal, as we have previously demonstrated (D'Cunha et al, 2013). Re-exposure to the selfadministration context increased extracellular DA levels in 

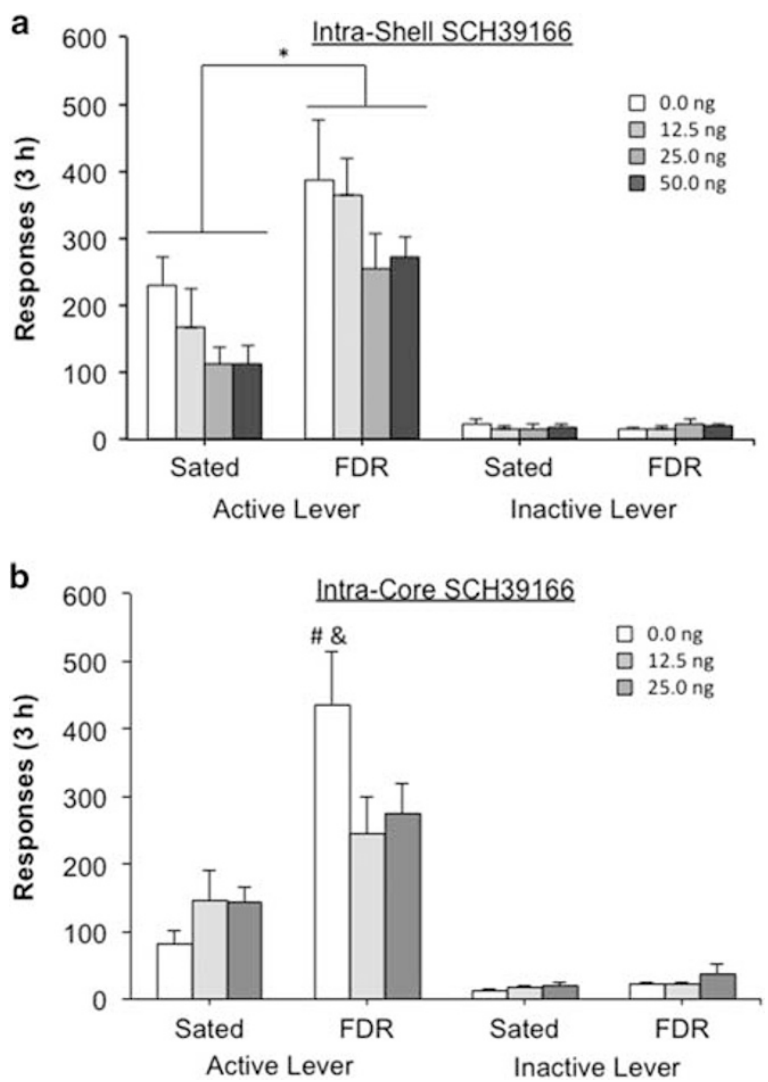

Figure 4 The effect of injections of the dopamine DI-like receptor antagonist SCH 39166 into the NAc shell (a) or NAc core (b) on the augmentation of heroin-seeking induced by chronic food restriction. $* p=0.05$ compared to the sated groups. ${ }^{*} p<0.000$ I FDR-0.0 ng group compared to sated-0.0 ng group. ${ }^{\&} p=0.02$ FDR-0.0 ng group compared to FDR- 12.5 ng group.

the NAc shell and core. However, the increase in extracellular DA levels in the NAc core occurred in both the sated and FDR rats, while in the NAc shell, exposure to the drug context selectively increased extracellular DA levels in FDR rats. Exposure to a novel context increased extracellular DA levels in the NAc core, but not shell, only in the FDR rats. Initiation of the heroin-seeking test maintained the increase in extracellular DA levels in the NAc shell and core of FDR rats. DA levels then quickly returned to baseline in the NAc core, while extracellular DA levels in the NAc shell remained elevated. Finally, administration of the DA D1-like receptor antagonist SCH39166 into the NAc shell decreased heroin seeking in both feeding conditions. In contrast, intra-NAc core SCH39166 decreased heroin seeking selectively in the FDR group.

\section{Effects of Exposure to Heroin-Associated Context on Extracellular DA in NAc Shell and Core in FDR and Sated Rats}

To the best of our knowledge, ours is the first report on changes in extracellular DA levels following exposure to a heroin-associated context, independent of the discrete drugassociated cues or instrumental contingency, in rats with a history of heroin self-administration.

Previous reports on conditioned changes in DA levels in the mesolimbic pathway terminals are inconsistent. Increases in extracellular DA in the NAc following exposure to an amphetamine- or cocaine-associated context have been reported (Duvauchelle et al, 2000a, b; Stuber et al, 2002). In contrast, other investigations did not find changes in extracellular or tissue DA levels following exposure to cocaine- or morphine-conditioned contextual stimuli (Walter and Kuschinsky, 1989; Brown and Fibiger, 1992). Unfortunately, in most of the studies cited above, no distinctions were made between the NAc shell and core. Importantly, even when changes in NAc extracellular DA levels were found following exposure to the drug context (Duvauchelle et al, 2000a, b; Stuber et al, 2002), those changes were not temporally or quantitatively associated with the conditioned behavioral response.

Stuber et al (2002) reported a conditioned increase in extracellular DA levels in the NAc core following exposure to an amphetamine-paired environment in sated rats, but not in FDR rats (to $90 \%$ of their baseline body weight). This finding contrasts with the statistically significant increase in extracellular DA levels in the NAc core that we observed in both the sated and FDR rats following exposure to the heroin selfadministration environment. However, in FDR rats, an increase in NAc core DA also occurred in a novel context, suggesting that the transfer between environments induced a non-specific DA response. This response might be more related to arousal than to conditioned drug effects (Brown and Fibiger, 1992). Discrepancies compared with previous reports on NAc DA response to drug-associated context could also result from the use of passive, Pavlovian conditioning, whereas instrumental conditioning was used here.

Mesolimbic DA is thought to be critically involved in the generation of incentive salience to drug-associated stimuli, leading to approach and engagement with the drug-related stimuli (Berridge, 2007). Since the generation of incentive salience is strongly modulated by physiological states (Berridge, 2007), this could explain the heroin-context specific increase in NAc shell DA in FDR rats. In the current study, rats' behavior in the operant conditioning chambers was not monitored during the 10-min period leading to the initiation of the heroin-seeking test. We therefore have no direct assessment of the association between the change in NAc DA levels and noninstrumental drug context-conditioned behaviors.

\section{Effects of Exposure to Heroin-Associated Discrete Cues on Extracellular DA in NAc Shell and Core in FDR and Sated Rats}

The increase in extracellular DA levels in the NAc shell and core that was selective to the FDR groups following the initiation of the heroin-seeking test, coincided with the intense active lever pressing over the first 10-min time bin. This suggests that food restriction-induced augmentation of heroin seeking is associated with increased NAc extracellular DA levels. As mentioned above, food restriction can sensitize neural systems that are involved in incentive motivational processes, including DA systems (Berridge and Robinson, 1998), resulting in cue-induced elevation of NAc core and shell DA in FDR rats. 
In contrast to our findings, Bassareo et al (2011, 2015) reported that exposure to sucrose- and morphineconditioned stimuli elevated DA levels only in the NAc shell. The differences between our results and those reported by Bassareo et al (2011) may be due to the use of Pavlovian/ contextual conditioned cues by Bassareo et al (2011), vs the instrumental/discrete cues in the present report. However, an explanation based on the difference in the conditioning procedures and the nature of the cues seems unlikely, since a selective increase in DA in the NAc shell, but not core, was reported by the same group (Bassareo et al, 2015) using an instrumental conditioning procedure with sucrose-associated discrete cues. Importantly, comparisons with the study by Bassareo et al (2015) should be made with caution, considering the non-drug reward used in their procedure and the known differential effects of non-drug and drug conditioned stimuli on DA transmission in the NAc (Bassareo et al, 2011). Thus, the reasons for the less selective increase in NAc DA reported here in both shell and core $v s$ the NAc shell selective effect reported by Bassareo et al $(2011,2015)$ are not clear.

Sated rats in the current study showed no statistically significant changes in DA levels in NAc shell or core during the heroin-seeking test. This finding is in line with the unaltered DA levels in the NAc following responsecontingent exposure to cocaine-associated cues reported by Ito et al (2000), and Neisewander et al (1996). Interestingly, rats in Ito et al (2000) study were mildly food restricted throughout the experiment. This apparent lack of foodrestriction effect on drug-cue-induced NAc DA could be explained by their experimental procedure that involved cocaine-seeking tests under a second-order schedule of reinforcement. In contrast, rats in the current study experienced a prolonged period of withdrawal before the heroin-seeking test. It has been established that behavioral and neurochemical adaptations occur over drug withdrawal periods, resulting in an enhanced response over time (incubation of drug craving; Grimm et al, 2001; Pickens et al, 2011).

Finally, extracellular DA in the NAc shell remained higher in the FDR group compared with the sated one throughout most of the heroin-seeking test, whereas lever pressing rapidly extinguished in both groups. Moreover, the initiation of the test session was characterized by robust heroin seeking, in both feeding condition groups, that is typically observed following a withdrawal period (Neisewander et al, 1996; Grimm et al, 2001; Shalev et al, 2001; Fuchs et al, 2008). This dissociation between levels of DA in the NAc and the magnitude of drug seeking has been noted in previous reports with cocaine- and herointrained rats (Wise et al, 1995; Neisewander et al, 1996; Ito et al, 2000).

Taken together, our data indicate that there is a weak, or no relation between changes in extracellular DA levels in the NAc shell and heroin-seeking following prolonged withdrawal, in both FDR and sated rats. In contrast, changes in DA levels in the NAc core seem to parallel the changes in lever pressing throughout the heroin-seeking test, but only in the FDR rats, suggesting a differential role for DA in NAc core in sated and FDR rats.
Effects of Intra-NAc Shell and Core Injections of SCH39166 on Heroin Seeking in FDR and Sated Rats

Notably, active lever responses performed by sated rats treated with intra-NAc core vehicle injections (0.0 ng SCH39166) were considerably lower compared with rats with intra-NAc shell vehicle injections. This could have prevented an effect of SCH39166 from being demonstrated (floor effect) in the sated intra-NAc core injected rats. Nevertheless, the sated vehicle-injected group performed a substantial number of lever responses ( $\sim 85$ lever presses), and under identical conditions, sated rats from the same cohorts did not show any attenuation of lever responding following treatment with SCH39166.

DA D1-like receptors in the NAc have been strongly implicated in context and discrete cue-induced drug seeking for alcohol (Chaudhri et al, 2009; Marchant and Kaganovsky, 2015), morphine (Gao et al, 2013), and heroin (Bossert et al, 2007). However, the involvement of D1-like receptors in the NAc shell $v s$ core seems to be dependent on the selfadministered substance, as well as on the drug-seeking procedure. Renewal of extinguished or punished alcohol seeking was attenuated by antagonism of D1-like receptors in either NAc shell or core (Chaudhri et al, 2009; Marchant and Kaganovsky, 2015). In contrast, blockade of D1-like receptors in the NAc shell, but not core, decreased contextinduced reinstatement of heroin seeking, while intra-core injections decreased discrete cue-induced reinstatement of heroin seeking (Bossert et al, 2007). Gao et al (2013) reported that D1-like receptor antagonism in the shell attenuated morphine seeking using an 'abstinence' procedure (similar to the one used here); however, the role of D1-like receptors in the core was not assessed in that study. The implied critical role for D1-like receptors in the NAc shell in context- and cue-induced drug-seeking corresponds with the attenuated heroin seeking, regardless of feeding condition, which we observed after intra-NAc shell injections of SCH39166.

Finally, considering the findings of Bossert et al (2007), the selective attenuation of heroin seeking in FDR rats that were injected with SCH39166 into the NAc core suggests that food restriction-induced augmentation of heroin seeking is mediated by an enhancement of the incentive motivational properties (Berridge and Robinson, 1998) of the discrete, rather than contextual, heroin-associated cues.

There are several methodological issues that should be considered when interpreting the present findings. First, although the DA microdialysis sampling intervals were comparatively short (10 $\mathrm{min})$, using this technique it is impossible to estimate very fast, phasic, changes in the DA signals that can be picked up using voltammetry ( 100 ms). However, the microdialysis approach, as utilized here, successfully identified changes in extracellular DA levels over behaviorally relevant epochs, such as the switch from context exposure to the beginning of the heroin-seeking session (Figure 3b). Second, it is important to note that the current experimental design does not allow a clear dissociation between the contribution of contextual and discrete cues to heroin seeking once the test session commenced, a caveat that should be addressed in future studies (see Shalev et al, 2002 for a discussion of the relevant challenges in dissociating the effects of discrete and contextual cue on drug seeking). Third, the observed effects of the intracranial 
SCH39166 injections might be due to diffusion of the antagonist into surrounding tissue. However, this is most unlikely, as indicated by the differential effect of injections into the adjacent core and shell compartments of the NAc. Finally, we did not assess the involvement of NAc DA D2-like receptors in the food restriction effect, as explained in the introduction. Future investigations should support this rational by targeting these receptors.

\section{CONCLUSION}

Context-induced changes in DA levels in the NAc core of FDR rats following a period of withdrawal suggest a non-specific arousal effect. In contrast, the heroin-context selective increase in NAc shell DA levels in FDR rats, when first exposed to the test chambers, might reflect an enhancement of the incentive properties of the contextual cues. Future studies will address this hypothesis. In the NAc shell, food restriction-induced changes in DA presynaptic mechanisms, reflected by changes in extracellular DA levels during the heroin-seeking test, or postsynaptic adaptations in D1-like receptor function were not closely associated with heroin-seeking driven by responsecontingent discrete cues. In contrast, in the NAc core, changes in extracellular DA levels paralleled heroin seeking in FDR rats, with increased DA levels at the beginning of the test session, when lever pressing was most vigorous, that subsequently decreased as heroin seeking declined. In addition, intra-NAc core injections of SCH39166 selectively decreased heroin seeking in FDR rats. We therefore conclude that changes in DA presynaptic mechanisms and postsynaptic adaptations in NAc core cells that express DA D1-like receptors mediate food restriction-induced augmentation of heroin seeking. The results we report for the sated rats support current neurobiological addiction theories that suggest a minor role for DA transmission in the NAc core in drug seeking (Kalivas and Volkow, 2005). However, in foodrestricted rats, DA in the NAc core has a critical role in the augmentation of heroin seeking. An interesting future direction would be to investigate the generalization of this role to other chronic stressors.

\section{FUNDING AND DISCLOSURE}

The authors declare no conflict of interest.

\section{ACKNOWLEDGMENTS}

This work was supported by the Natural Sciences \& Engineering Council (NSERC) Discovery Program (to US: 298915), the Fonds de recherche du Quebec - Santé (to CSBN), and the Canada Research Chairs program (to US). TMD and FS were funded by NSERC (PGS D and CGS D, respectively).

\section{REFERENCES}

Bassareo V, Cucca F, Musio P, Lecca D, Frau R, Di Chiara G (2015). Nucleus accumbens shell and core dopamine responsiveness to sucrose in rats: role of response contingency and discriminative/ conditioned cues. Eur J Neurosci 41: 802-809.

Bassareo V, Musio P, Di Chiara G (2011). Reciprocal responsiveness of nucleus accumbens shell and core dopamine to food- and drug-conditioned stimuli. Psychopharmacology (Berl) 214: 687-697.

Berridge KC (2007). The debate over dopamine's role in reward: The case for incentive salience. Psychopharmacology 191: 391-431.

Berridge KC, Robinson TE (1998). What is the role of dopamine in reward: Hedonic impact, reward learning, or incentive salience? Brain Res Brain Res Rev 28: 309-369.

Bossert JM, Poles GC, Wihbey KA, Koya E, Shaham Y (2007). Differential effects of blockade of dopamine D1-family receptors in nucleus accumbens core or shell on reinstatement of heroin seeking induced by contextual and discrete cues. J Neurosci 27: 12655-12663.

Brown EE, Fibiger HC (1992). Cocaine-induced conditioned locomotion: absence of associated increases in dopamine release. Neuroscience 48: 621-629.

Carr KD, Tsimberg Y, Berman Y, Yamamoto N (2003). Evidence of increased dopamine receptor signaling in food-restricted rats. Neuroscience 119: 1157-1167.

Carr KD, Chau LS, Cabeza de Vaca S, Gustafson K, Stouffer M, Tukey DS et al (2010). AMPA receptor subunit GluR1 downstream of D-1 dopamine receptor stimulation in nucleus accumbens shell mediates increased drug reward magnitude in food-restricted rats. Neuroscience 165: 1074-1086.

Carroll ME, Meisch RA (1981). Determinants of increased drug selfadministration due to food deprivation. Psychopharmacology 74: 197-200.

Carroll ME, Meisch RA (1984). Increased drug-reinforced behavior due to food deprivation. In: Thompson T, Dews PB, Barrett JE (eds). Advances in Behavioral Pharmacology. Academic Press: New York. pp 47-88.

Chaudhri N, Sahuque LL, Janak PH (2009). Ethanol seeking triggered by environmental context is attenuated by blocking dopamine D1 receptors in the nucleus accumbens core and shell in rats. Psychopharmacology (Berl) 207: 303-314.

Cheskin LJ, Hess JM, Henningfield J, Gorelick DA (2005). Calorie restriction increases cigarette use in adult smokers. Psychopharmacology 179: 430-436.

D'Cunha TM, Sedki F, Macri J, Casola C, Shalev U (2013). The effects of chronic food restriction on cue-induced heroin seeking in abstinent male rats. Psychopharmacology (Berl) 225: 241-250.

Duvauchelle CL, Ikegami A, Asami S, Robens J, Kressin K, Castaneda E (2000a). Effects of cocaine context on NAcc dopamine and behavioral activity after repeated intravenous cocaine administration. Brain Res 862: 49-58.

Duvauchelle CL, Ikegami A, Castaneda E (2000b). Conditioned increases in behavioral activity and accumbens dopamine levels produced by intravenous cocaine. Behav Neurosci 114: 1156-1166.

Fenu S, Spina L, Rivas E, Longoni R, Di Chiara G (2006). Morphineconditioned single-trial place preference: role of nucleus accumbens shell dopamine receptors in acquisition, but not expression. Psychopharmacology (Berl) 187: 143-153.

Fuchs RA, Lasseter HC, Ramirez DR, Xie X (2008). Relapse to drug seeking following prolonged abstinence: the role of environmental stimuli. Drug Discov Today Dis Models 5: 251-258.

Gaiardi M, Bartoletti M, Bacchi A, Gubellini C, Babbini M (1987). Increased sensitivity to the stimulus properties of morphine in food deprived rats. Pharmacol Biochem Behav 26: 719-723.

Gao J, Li Y, Zhu N, Brimijoin S, Sui N (2013). Roles of dopaminergic innervation of nucleus accumbens shell and dorsolateral caudate-putamen in cue-induced morphine seeking after prolonged abstinence and the underlying D1- and D2-like receptor mechanisms in rats. J Psychopharmacol 27: 181-191.

Grimm JW, Hope BT, Wise RA, Shaham Y (2001). Incubation of cocaine craving after withdrawal. Nature 412: 141-142.

Hall SM, Tunstall CD, Vila KL, Duffy J (1992). Weight gain prevention and smoking cessation: cautionary findings. $\mathrm{Am} \mathrm{J}$ Public Health 82: 799-803. 
Ito R, Dalley JW, Howes SR, Robbins TW, Everitt BJ (2000). Dissociation in conditioned dopamine release in the nucleus accumbens core and shell in response to cocaine cues and during cocaine-seeking behavior in rats. J Neurosci 20: 7489-7495.

Jung C, Rabinowitsch A, Lee WT, Zheng D, de Vaca SC, Carr KD (2016). Effects of food restriction on expression of place conditioning and biochemical correlates in rat nucleus accumbens. Psychopharmacology (Berl) 233: 3161-3172.

Kalivas PW, Volkow ND (2005). The neural basis of addiction: a pathology of motivation and choice. Am J Psychiatry 162: 1403-1413.

Krahn D, Kurth C, Demitrack M, Drewnowski A (1992). The relationship of dieting severity and bulimic behaviors to alcohol and other drug use in young women. $J$ Subst Abuse 4: 341-353.

Marchant NJ, Kaganovsky K (2015). A critical role of nucleus accumbens dopamine D1-family receptors in renewal of alcohol seeking after punishment-imposed abstinence. Behav Neurosci 129: 281-291.

Marchant NJ, Kaganovsky K, Shaham Y, Bossert JM (2015). Role of corticostriatal circuits in context-induced reinstatement of drug seeking. Brain Res 1628: 219-232.

Neisewander JL, O'Dell LE, Tran-Nguyen LT, Castaneda E, Fuchs RA (1996). Dopamine overflow in the nucleus accumbens during extinction and reinstatement of cocaine self administration behavior. Neuropsychopharmacology 15: 506-514.

Paxinos G, Watson C. The rat brain in stereotaxic coordinates, 5 th edn. Elsevier Academic Press: Burlington, 2005.

Pickens CL, Airavaara M, Theberge F, Fanous S, Hope BT, Shaham Y (2011). Neurobiology of the incubation of drug craving. Trends Neurosci 34: 411-420.
Sedki F, D'Cunha T, Shalev U (2013). A procedure to study the effect of prolonged food restriction on heroin seeking in abstinent rats. J Vis Exp e50751.

Shalev U, Grimm JW, Shaham Y (2002). Neurobiology of relapse to heroin and cocaine seeking: a review. Pharmacol Rev 54: 1-42.

Shalev U, Morales M, Hope BT, Yap J, Shaham Y (2001). Time dependent changes in extinction behavior and stress-induced reinstatement of drug seeking during heroin withdrawal. Psychopharmacology 156: 98-107.

Sorge RE, Rajabi H, Stewart J (2005). Rats maintained chronically on buprenorphine show reduced heroin and cocaine seeking in tests of extinction and drug-induced reinstatement. Neuropsychopharmacology 30: 1681-1692.

Stuber GD, Evans SB, Higgins MS, Pu Y, Figlewicz DP (2002). Food restriction modulates amphetamine-conditioned place preference and nucleus accumbens dopamine release in the rat. Synapse 46: 83-90.

Tobin S, Sedki F, Abbas Z, Shalev U (2013). Antagonism of the dopamine D1-like receptor in mesocorticolimbic nuclei attenuates acute food deprivation-induced reinstatement of heroin seeking in rats. Eur J Neurosci 37: 972-981.

Walter S, Kuschinsky K (1989). Conditioning of morphine-induced locomotor activity and stereotyped behaviour in rats. J Neural Transm Gen Sect 78: 231-247.

Wise RA, Leone P, Rivest R, Leeb K (1995). Elevations of nucleus accumbens dopamine and DOPAC levels during intravenous heroin self-administration. Synapse 21: 140-148.

Zacny JP, Lichtor JL, Zaragoza JG, de Wit H (1992). Effects of fasting on responses to intravenous fentanyl in healthy volunteers. J Subst Abuse 4: 197-207.

Supplementary Information accompanies the paper on the Neuropsychopharmacology website (http://www.nature.com/npp) 